\title{
Synthesis and Characterization of $N$-(2-Ethylhexyl)carbazole-2,3-Bis(4-fluorophenyl))thieno[3,4-b]pyrazine Copolymer
}

\author{
Ji-Cheng Li, Mi-Lim Hwang, Eun-Woo Lee, Soo-Hyoung Lee, Soo-Chang Yu, ${ }^{\dagger}$ and Youn-Sik Lee* \\ Division of Chemical Engineering, Nanomaterials Processing Research Center, Chonbuk National University, \\ Chonju, Chonbuk 561-756, Korea. E-mail: yosklear@chonbuk.ac.kr \\ ${ }^{\dagger}$ Deaprtment of Chemistry, Kunsan National University, Kunsan, Chonbuk 573-701, Korea \\ Received August 11, 2009, Accepted May 24, 2010
}

Key Words: $N$-(2-Ethylhexyl)carbazole, 2,3-Bis(4-fluorophenyl)thieno[3,4- $b$ ]pyrazine, Conjugated polymer, Low band-gap polymer

The discovery of bulk heterojunction solar cells has stimulated research in low band-gap $\pi$-conjugated polymers. ${ }^{1}$ The low band-gap polymers absorb a large part of the solar spectrum, and these $p$-type polymers (electron donors) can be used in the fabrication of photovolatic devices in combination with $[6,6]-$ phenyl- $\mathrm{C}_{61}$-butyric acid methyl ester (PCBM) as an n-type material (electron acceptor). Poly(3-hexylthiophene) (P3HT), with an optical band-gap $\left(\mathrm{E}_{\mathrm{g}}\right)$ of $\sim 2.0 \mathrm{eV}$, has been most frequently used along with PCBM in fabrication of polymer-based solar cells with power conversion efficiencies up to $\sim 5 \%$., However, conjugated polymers with lower $\mathrm{E}_{\mathrm{g}} \mathrm{s}$ than that of P3HT can lead to more enhanced absorption of sunlight, potentially increasing the photocurrent. The most common strategy to synthesize a low band-gap polymer involves incorporation of electron-rich units (donors) and electron-deficient units (acceptors) in an alternating fashion in the polymer chain. ${ }^{4}$

We have been attempting to synthesize various $p$-type polymers for applications in polymer-based photovoltaic devices. ${ }^{5-7}$ Thieno[3,4- $b]$ pyrazines have been shown to be excellent precursors for the production of low $\mathrm{E}_{\mathrm{g}} \pi$-conjugated polymers. ${ }^{8}$ Carbazole derivatives have received much attention as optical materials due to their special electrical- and photo-chemical properties, as they have planar conjugated structures and exhibit good hole-transporting as well as good electron-donating properties. ${ }^{9}$ Thus, it seemed a promising approach to study polymers consisting of alternating carbazole and thienopyrazine derivatives as electron-donating and electron-accepting units, respectively.

Recently, we synthesized an alternating copolymer consisting of 2,3-dimethylthieno[3,4- $b]$ pyrazine and $N$-(2-ethylhexyl) carbazole units. ${ }^{10}$ However, the optical $E_{g}$ of the polymer $(1.87 \mathrm{eV})$ was not much lower than that of P3HT. ${ }^{2,3}$ In this study, with a hope that incorporation of phenyl substituents instead of methyl groups on the pyrazine moiety may further decrease the $\mathrm{E}_{\mathrm{g}}$ due to the increased conjugation in the thieno[3,4- $\left.b\right]$ pyrazine unit, we synthesized an alternating copolymer consisting of 2,3-bis(4-fluorophenyl)thieno[3,4-b]pyrazine and $N$-(2-ethylhexyl)carbazole units.

\section{Experimental Section}

Materials. All chemical reagents were purchased from Ald- rich and used without further purification. 3,6-Bis(4,4,5,5-tetramethyl-1,3,2-dioxaborolane)- $N$-(2-ethylhexyl)carbazole was prepared with three steps from carbazole, according to a reported procedure. ${ }^{8}$ 3,4-Diaminothiophene dihydrochloride was prepared with three steps from thiophene, according to reported procedures. $^{11,12}$

2,3-Bis(4-fluorophenyl)thieno[3,4-b]pyrazine (1): A mixture of 4,4'-difluorobenzil (2.46 g, $10 \mathrm{mmol}), 3$,4-diaminothiophene hydrochloride $(1.87 \mathrm{~g}, 10 \mathrm{mmol})$, and triethylamine $(20 \mathrm{~mL})$ in dichloromethane $(70 \mathrm{~mL})$ and ethanol $(70 \mathrm{~mL})$ was stirred at $50{ }^{\circ} \mathrm{C}$ for $8 \mathrm{~h}$. After cooling, the reaction solution was extracted with dichloromethane and water $(1 / 1)$. The organic layer was collected and dried over anhydrous magnesium sulfate. Further purification was performed using silica gel flash column chromatography (chloroform) to generate a dark yellow solid $(2.11 \mathrm{~g}, 65 \%) .{ }^{1} \mathrm{H} \mathrm{NMR}\left(\mathrm{CDCl}_{3}, \delta\right) 7.13(\mathrm{~m}, 4 \mathrm{H}), 7.51(\mathrm{~m}$, $4 \mathrm{H}), 8.21(\mathrm{~s}, 2 \mathrm{H}) ;{ }^{13} \mathrm{C} \mathrm{NMR}\left(\mathrm{CDCl}_{3}, \delta\right) 115.6,117.8,131.6$, 135.1, 141.5, 152.1, 161.9; IR ( $\left.\mathrm{KBr}, \mathrm{cm}^{-1}\right) 3073,1596,1513$, 1406, 1359, 1287, 1222, 1157, 1104, 1050, 973, 836, 813, 736, 700, 647; Anal. Calcd: $\mathrm{C}_{18} \mathrm{H}_{10} \mathrm{~F}_{2} \mathrm{~N}_{2} \mathrm{~S}$ : C, 66.65; H, 3.11: N, 8.64; S, 9.89. Found: C, 66.36; H, 3.06; N, 8.32; S, 10.01 .

5,7-Dibromo-2,3-bis(4-fluorophenyl)thieno[3,4-b]pyrazine (2): Compound 2 was prepared through a modification of a previously reported method. ${ }^{12}$ A solution of $N$-bromosuccinimide (NBS) (3.8 g, $21 \mathrm{mmol})$ in $\mathrm{N}, \mathrm{N}$-dimethylformamide (DMF) $(100 \mathrm{~mL})$ was added dropwise to a solution of compound 1 $(3.24 \mathrm{~g}, 10 \mathrm{mmol})$ in DMF $(250 \mathrm{~mL})$ that was cooled by an ice-water bath. After addition, the ice-water bath was removed and the mixture was allowed to warm to room temperature and stirred for $6 \mathrm{~h}$. The mixture was poured into water $(400 \mathrm{~mL})$ and the product was extracted with chloroform. Organic layers were combined, washed with saturated aqueous sodium chloride, dried over anhydrous magnesium sulfate, and concentrated by rotary evaporation. Further purification was performed using silica gel flash column chromatography (chloroform/ hexane, $2 / 1)$ to generate a green solid $(3.66 \mathrm{~g}, 76 \%) .{ }^{1} \mathrm{H} \mathrm{NMR}$ $\left(\mathrm{CDCl}_{3}, \delta\right) 7.03(\mathrm{~m}, 4 \mathrm{H}), 7.43(\mathrm{~m}, 4 \mathrm{H})$; IR $\left(\mathrm{KBr}, \mathrm{cm}^{-1}\right) 1596$, 1513, 1411, 1365, 1269, 1234, 1157, 1104, 1074, 979, 836, 736, 647, 606; Anal. Calcd: $\mathrm{C}_{18} \mathrm{H}_{8} \mathrm{Br}_{2} \mathrm{~F}_{2} \mathrm{~N}_{2} \mathrm{~S}$ : C, 44.84; H, 1.67 : N, 5.81; S, 6.65. Found: C, 45.47; H, 1.43; N, 6.32; S, 6.91.

Poly(3,6-(N-2-ethylhexyl)carbazole-alt-2,3-bis(4-fluorophenyl)thieno[3,4-b]pyrazine) (PEC-FTP): 3,6-Bis $(4,4,5,5-$ 
tetramethyl-1,3,2-dioxaborolane)-9-( $N$-2-ethylhexyl)carbazole $(0.482 \mathrm{~g}, 1.0 \mathrm{mmol})$, compound $2(0.531 \mathrm{~g}, 1.0 \mathrm{mmol})$, and $\mathrm{Pd}\left(\mathrm{PPh}_{3}\right)_{4}(69 \mathrm{mg}, 6 \mathrm{~mol} \%)$ were dissolved in $30 \mathrm{~mL}$ of toluene, followed by the addition of aqueous potassium carbonate $(2.0 \mathrm{M}, 30 \mathrm{~mL})$, and vigorously stirred at $90{ }^{\circ} \mathrm{C}$ for $72 \mathrm{~h}$ under nitrogen. For end-capping, 2-bromo-3-hexylthiophene $(0.05 \mathrm{~g}, 0.20 \mathrm{mmol})$ was added, reacted for $6 \mathrm{~h}$, followed by the addition of 2-(4,4,5,5-tetramethyl-1,3,2-dioxaborolane)4-hexylthiophene $(0.12 \mathrm{~g}, 0.41 \mathrm{mmol})$. The resulting solution was allowed to react for $6 \mathrm{~h}$, cooled, poured slowly into methanol, collected by filtration, and washed by Soxhlet extraction with acetone, hexanes, and chloroform. The chloroform fraction $(550-600 \mathrm{~mL})$ was reduced to $40-50 \mathrm{~mL}$ under reduced pressure, precipitated into methanol, filtered, and finally airdried overnight $(0.43 \mathrm{~g}, 72 \%)$. ${ }^{1} \mathrm{H} \mathrm{NMR}\left(\mathrm{CDCl}_{3}, \delta\right)$ 0.6-1.8 (br, $\left.\mathrm{CH}_{2}, \mathrm{CH}_{3}\right), 2.2$ (br, carbazole $\left.\beta-\mathrm{CH}\right), 4.17\left(\mathrm{br}\right.$, carbazole $\alpha-\mathrm{CH}_{2}$ ), 6.9-9.0 (br, carbazole aromatic CH); IR $\left(\mathrm{KBr}, \mathrm{cm}^{-1}\right)$ 2959, 2924, 2860, 1602, 1507, 1454, 1359, 1306, 1234, 1157, 1074, 979, $836,813,730,647,606$.

Measurements. NMR spectra were recorded using a JEOL FT-NMR (400 MHz) spectrometer. FT-IR spectra were recorded using a JASCO-4100 FT-IR spectrophotometer. Gel permeation chromatography (GPC) was performed on a PL-GPC110 with a RI detector using chloroform as the eluent and polystyrene as the standard, respectively. UV-visible absorption and photoluminescence (PL) emission spectra were obtained using a JASCO V-670 spectrofluorometer. Cyclic voltammetric (CV) measurements were performed on a Versa STAT 3, using a $0.10 \mathrm{M}$ solution of tetrabutylammonium tetrafluoroborate $\left(n-\mathrm{Bu}_{4} \mathrm{NBF}_{4}\right)$ in chloroform under argon at a scan rate of 50 $\mathrm{mV} / \mathrm{s}$ at room temperature. A Pt wire and $\mathrm{Ag} / \mathrm{Ag}^{+}$were used as the counter and reference electrodes, respectively.

Fabrication of photovoltaic devices. Photovoltaic devices were fabricated with the configuration of ITO/PEDOT:PSS/ PEC-FTP:PCBM/LiF/Al, possessing an active area of $12 \mathrm{~mm}^{2}$, as described in our previous paper. ${ }^{5}$ The active layer (thickness $\sim 110 \mathrm{~nm}$ ) was prepared onto the surface of PEDOT:PSS (thickness $\sim 40 \mathrm{~nm}$ ), via spin-coating using blends of PEC-FTP and PCBM in dichlorobenzene/chloroform (1/1, v/v). Subsequently, the active layer was dried at $120{ }^{\circ} \mathrm{C}$ for $10 \mathrm{~min}$ under a nitrogen atmosphere. An Al layer with a thickness of $150 \mathrm{~nm}$ ( $\mathrm{LiF} \sim 1 \mathrm{~nm}$ ) was deposited via thermal evaporation under vacuum $\left(10^{-6}\right.$ torr $)$. The I-V characteristics of the photovoltaic devices were measured using an AM 1.5G solar simulator (Newport) at $100 \mathrm{~mW} / \mathrm{cm}^{2}$ conditions. ${ }^{5}$

\section{Results and Discussion}

The synthesis of PEC-FTP is outlined in Scheme 1. Treatment of 3,4-diaminothiophene dihydrochloride with 4,4'-difluorobenzil in the presence of triethylamine afforded 2,3-bis (4-fluorophenyl)thieno[3,4-b]pyrazine (compound 1), which was then brominated with NBS to give 5,7-dibromo-2,3-bis (4-fluorophenyl)thieno[3,4-b]pyrazine (compound 2). Finally, compounds 2 and bis(4,4,5,5-tetramethyl-1,3,2-dioxaborolane)9-(N-2-ethylhexyl)carbazole were copolymerized via Suzuki coupling, and the resulting polymer was end-capped with successive treatments of 2-bromo-3-hexylthiophene and 2-(4,4,5,5tetramethyl-1,3,2-dioxaborolane)-4-hexylthiophene to obtain the target polymer, PEC-FTP. The polymer was readily soluble in common organic solvents such as chloroform, dichloromethane, chlorobenzene, etc. According to GPC measurements, the number- and weight-average molecular weight $\left(\mathrm{M}_{\mathrm{n}} / \mathrm{M}_{\mathrm{w}}\right)$ of PEC-FTP was estimated to be 9100 and 15400, respectively.

A solution of PEC-FTP in chloroform absorbed light in a spectral range from UV to near $740 \mathrm{~nm}$, with absorption peaks at 339 and $564 \mathrm{~nm}$, and showed a PL peak at $629 \mathrm{~nm}$. However, the solid film of PEC-FTP exhibited absorption peaks at 336 and $600 \mathrm{~nm}$, and a PL emission peak at $689 \mathrm{~nm}$ (Fig. 1). Obviously, the absorption peak at $564 \mathrm{~nm}$ (solution) and $600 \mathrm{~nm}$ (solid film) are originated from the conjugated $\pi$-system of PEC-FTP. The bathochromic shifts of the UV-visible absorption and PL emission spectra of the polymer film, as compared

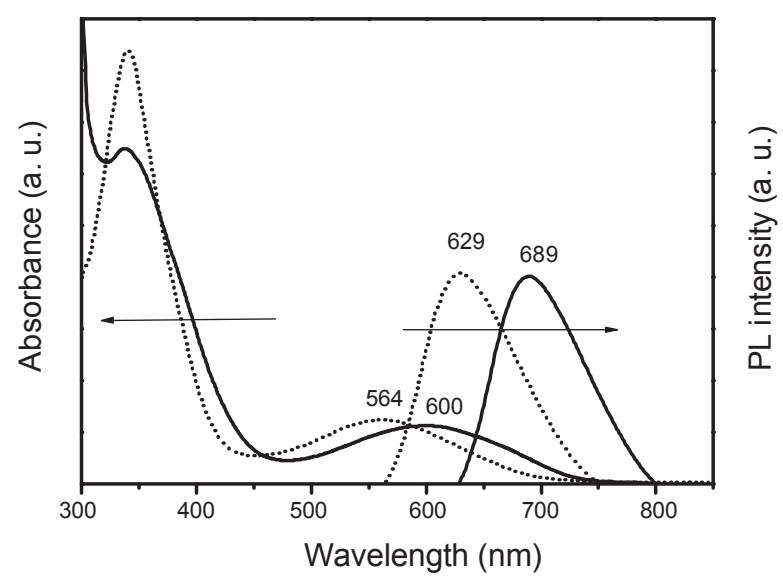

Figure 1. UV-visible absorption and PL emission spectra of PEC-FTP in chloroform (dotted lines) and film (solid lines).
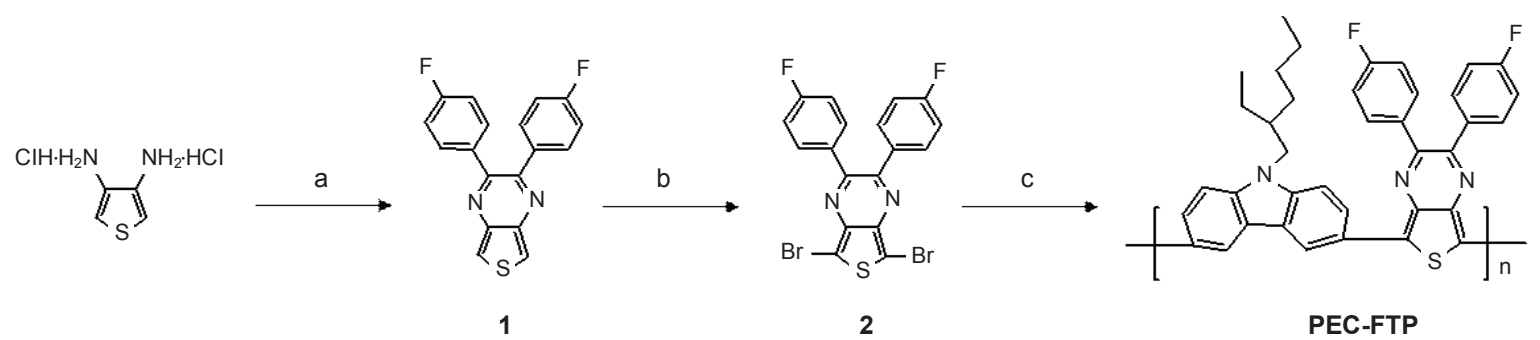

Scheme 1. Synthetic route to PEC-FTP: (a) 4,4'-difluorobenzil, triethylamine, dichloromethane/ethanol (1/1); (b) NBS, DMF; (c) 3,6-bis(4,4,5,5tetramethyl-1,3,2-dioxaborolane)-9-(N-2-ethylhexyl)carbazole, $\mathrm{Pd}\left(\mathrm{PPh}_{3}\right)_{4}, \mathrm{~K}_{2} \mathrm{CO}_{3}$, toluene. 


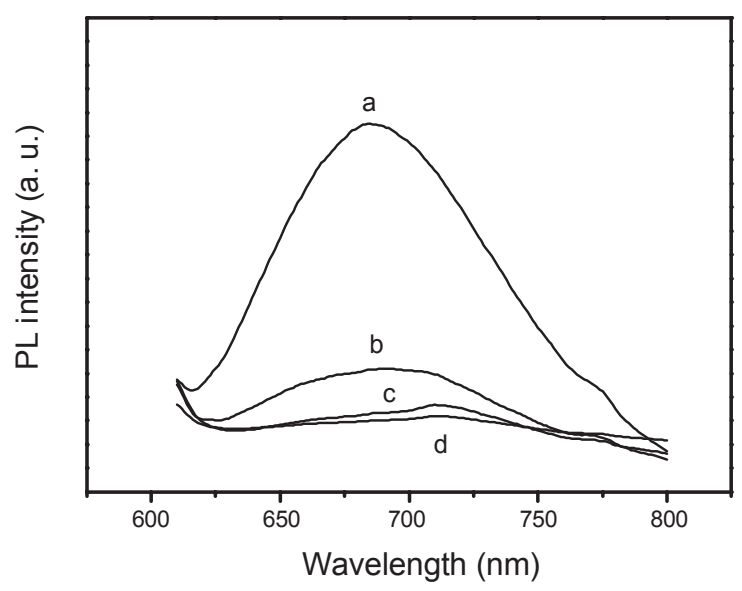

Figure 2. PL emission spectra of various weight ratios of PEC-FTP to PCBM in film: (a) 1:0, (b) 1:1, and (c) 1:3.

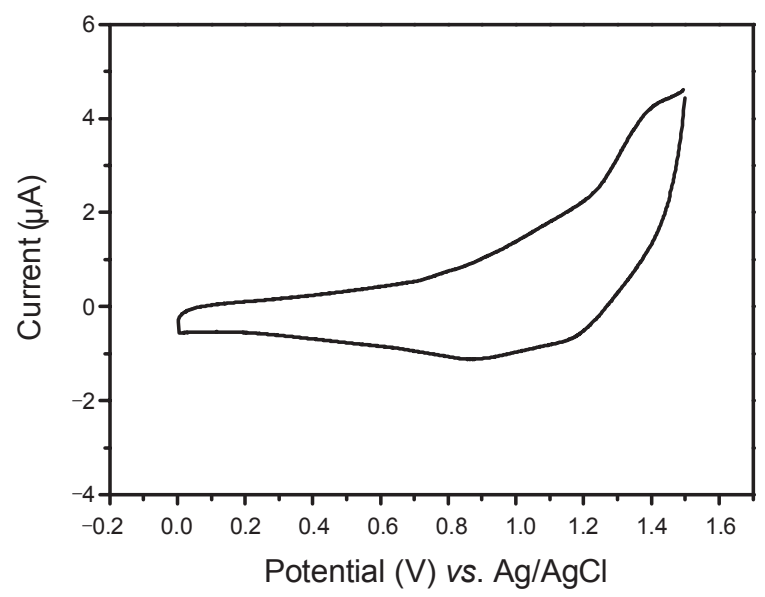

Figure 3. Cyclic voltammogram curve of PEC-FTP in chloroform $(0.40 \mathrm{mg} / \mathrm{mL})$ containing $0.10 \mathrm{M} \mathrm{Bu}_{4} \mathrm{NBF}_{4}$.

to those of its solution sample, are due to closer intermolecular interactions in solid state. ${ }^{13}$

PL spectra for blends of PEC-FTP/PCBM in film revealed that, with increasing PCBM content, the PL intensity of PECFTP progressively decreased accordingly, due to more efficient quenching of the polymer's PL emissions by PCBM (Fig. 2). This observation clearly indicates that the electron transfer efficiency from the photo-excited PEC-FTP to PCBM increases as the PCBM content increases, due to the shortened distances between the polymer and PCBM molecules in the solid films.

The electrochemical property of PEC-FTP was examined by $\mathrm{CV}$ experiments in a three-electrode cell, set up with $0.10 \mathrm{M}$ $n$-Bu $\mathrm{NBF}_{4}$ supporting electrolyte in chloroform (Fig. 3). In the anodic scan, the onset of oxidation potential ( $\left.\mathrm{E}_{\text {ox, onset }}\right)$ of PEC-FTP occurred at $0.77 \mathrm{~V}$. The highest occupied molecular orbital (HOMO) energy level of PEC-FTP was estimated to be $-5.48 \mathrm{eV}$, according to the empirical formula $\mathrm{HOMO}=$ - $\left(\mathrm{E}_{\mathrm{ox}}\right.$, onset +4.71$)(\mathrm{eV}){ }^{14}$ The optical $\mathrm{E}_{\mathrm{g}}$ of PEC-FTP was estimated to be $1.68 \mathrm{eV}$, based on the lower energy absorption band edge $(736 \mathrm{~nm})$ of the UV-visible absorption spectrum in film. ${ }^{6}$ If this polymer is employed as a $p$-type polymer along with PCBM as the $n$-type material in the fabrication of photo-
Table 1. Summary of the optical and electrochemical data of PEC-FTP

\begin{tabular}{ccccccc}
\hline $\begin{array}{c}\lambda_{\mathrm{ab}, \text { onset }} \\
(\text { film) }(\mathrm{nm})\end{array}$ & $\begin{array}{c}\lambda_{\mathrm{PL}, \max } \\
(\text { film })(\mathrm{nm})\end{array}$ & $\begin{array}{c}\mathrm{E}_{\text {ox, onset }} \\
(\mathrm{V})\end{array}$ & $\begin{array}{c}\mathrm{E}_{\mathrm{g}}{ }^{a} \\
(\mathrm{eV})\end{array}$ & $\begin{array}{c}\text { HOMO } \\
(\mathrm{eV})\end{array}$ & $\begin{array}{c}\text { LUMO } \\
(\mathrm{eV})\end{array}$ \\
\hline PEC-FTP & 736 & 689 & 0.77 & 1.68 & -5.48 & -3.80
\end{tabular}

${ }^{\bar{a}} \mathrm{E}_{\mathrm{g}}(\mathrm{eV})=1240 / \lambda_{\mathrm{ab}, \text { onset }}$

voltaic cells, the lower HOMO energy level of PEC-FTP as compared to that of P3HT (HOMO $\sim 5.1 \sim-5.2 \mathrm{eV})$ would be advantageous with respect to the open-circuit voltage $\left(\mathrm{V}_{\mathrm{oc}}\right)$, since the $\mathrm{V}_{\mathrm{oc}}$ is closely related to the difference in energy level between the HOMO of a $p$-type polymer and the lowest unoccupied molecular orbital (LUMO) of PCBM. ${ }^{15}$ From the correlation between the HOMO energy level and the optical $\mathrm{E}_{\mathrm{g}}$, the LUMO energy level of PEC-FTP was calculated to be $-3.80 \mathrm{eV}$. It was reported that the difference in the LUMO energy levels of the $p$-type and $n$-type materials should be slightly larger than the exciton binding energy for efficient electron transfer. ${ }^{16}$ The difference in the LUMO energy levels of PEC-FTP and PCBM was calculated to be $\sim 0.5 \mathrm{eV}$, suggesting that the polymer can be used as a $p$-type material in fabrication of polymerbased photovoltaic devices. The lower energy-band edge of the UV-visible absorption ( $\lambda_{\mathrm{ab}}$, onset $), \mathrm{E}_{\mathrm{ox}}$, onset, $\mathrm{E}_{\mathrm{g}}$, and $\mathrm{HOMO} /$ LUMO energy of PEC-FTP are listed in Table 1.

Bulk heterojunction photovoltaic devices were fabricated using various ratios of PEC-FTP:PCBM $(1: 1,1: 2$, and 1:3) in dichlorobenzene/chloroform $(1: 1, \mathrm{v} / \mathrm{v})$. The open circuit voltage $\left(\mathrm{V}_{\mathrm{oc}}\right)$, short circuit current density $\left(\mathrm{J}_{\mathrm{sc}}\right)$, fill factor $(\mathrm{FF})$, and power conversion efficiency (PCE) of the device prepared using a solution of PEC-FTP:PCBM (1:2) were estimated to be $0.39 \mathrm{~V}$, $0.16 \mathrm{~mA} / \mathrm{cm}^{2}, 0.26$, and $0.016 \%$, respectively. The conversion efficiencies of the photovoltaic devices, fabricated using 1:1 and 1:2 ratios of PEC-FTP/PCBM under the identical experimental conditions were $0.006 \%$ and $0.014 \%$, respectively. The even lower PCE of the 1:1 PEC-FTP:PCBM device, compared to those of the 1:2 and 1:3 PEC-FTP:PCBM devices, can be ascribed to inefficient dissociation of excitons at the interface between the polymer and PCBM, based on Figure 2 where the PL emission of PEC-FTP was not completely quenched by PCBM when the ratio of PEC-FTP to PCBM was 1:1. Even though more device optimizations may enhance the performance of the devices to some extent, a main reason for the currently low conversion efficiency seems to be the low absorption coefficient of the polymer since the absorbance of PEC-FTP at $564 \mathrm{~nm}$ was about one tenth of P3HT's absorbance at $448 \mathrm{~nm}$ in chloroform at the same concentration.

\section{Conclusions}

PEC-FTP was successfully synthesized via a multi-step procedure. The optical band gap of the polymer was estimated to be $1.68 \mathrm{eV}$, which is much lower than that of P3HT. The LUMO and HOMO energy levels of PEC-FTP were estimated to be $-3.80 \mathrm{eV}$ and $-5.48 \mathrm{eV}$, respectively. However, the PCE of the photovoltaic devices fabricated using the polymer:PCBM $(1: 2)$ was only $0.016 \%$ under conditions of $100 \mathrm{~mW} / \mathrm{cm}^{2}$ and AM $1.5 \mathrm{G}$ illumination. The low efficiency of the present devices was 
attributed the very low absorption coefficient of the polymer, as compared to P3HT.

Acknowledgments. This work was supported by the Korea Research Foundation Grant, funded by the Korea Government (MOEHERD) (KRF-2007-521-C00198).

\section{References}

1. Campos, L. M.; Tontcheva, A.; Guenes, S.; Sonmez, G.; Neugebauer, H.; Sariciftci, N. S.; Wudl, F. Chem. Mater. 2005, 17, 4031.

2. Ma, W.; Yang, C.; Gong, X.; Lee, K.; Heeger, A. J. Adv. Funct. Mater. 2005, 15, 1617.

3. Kim, J. Y.; Kim, S. H.; Lee, H.-H.; Lee, K.; Ma, W.; Gong, X.; Heeger, A. J. Adv. Mater. 2006, 18, 572.

4. Zoombelt, A. P.; Gilot, J.; Wienk, M. M.; Janssen, R. A. J. Chem. Mater. 2009, 21, 1663.

5. Li, J.-C.; Lee, H.-Y.; Lee, S.-H.; Zong, K. K.; Jin, S.-H.; Lee, Y.-S. Synth. Met. 2009, 159, 201.
6. Li, J.-C.; Meng, Q. B.; Kim, J.-S.; Lee, Y.-S. Bull. Korean Chem. Soc. 2009, 30, 951.

7. Li, J.-C.; Kim, S.-J.; Lee, S.-H.; Zong, K. K.; Lee, Y.-S. Macromol. Res. 2009, 17, 356.

8. Wang, X.; Perzon, E.; Langa, F. F.; Admassie, S.; Anderson, M. R.; Inganas, O. Adv. Funct. Mater. 2005, 15, 1665.

9. Yoonb, K. R.; Byuna, N. M.; Lee, H. Synth. Met. 2007, 157, 603.

10. Li, J.-C.; Seo, E.-O.; Lee, S.-H.; Lee, Y.-S. Macromol. Res. 2010 , 18, 304.

11. Kenning, D. D.; Mitchell, K. A.; Calhoun, T. R.; Funfar, Me. R.; Sattler, D. J.; Rasmussen, S. C. J. Org. Chem. 2002, 67, 9073.

12. Chen, Z. H.; Bouffard, J.; Kooi, S. E.; Swager, T. M. Macromolecules 2008, 41, 6672.

13. Moses, D.; Dogariu, A.; Heeger, A. J. Phy. Rev. B 2000, 61, 9373.

14. Zhu, Y.; Rabindranath, A. R.; Beyerlein, T.; Tieke, B. Macromolecules 2007, 40, 6981.

15. Scharber, M. C.; Muhlbacher, D.; Koppe, M.; Denk, P.; Waldauf, C.; Heeger, A. J.; Brabec, C. J. Adv. Mater. 2006, 18, 789.

16. Thompson, B. C.; Kim, Y-G.; McCarley, T. D.; Reynolds, J. R. J. Am. Chem. Soc. 2006, 128, 12714. 